\title{
Ileal Occlusion on Bezoars at Kati BSS Hospital
}

\author{
Keita Koniba1 $^{*}$, Abdoulaye Diarra ${ }^{1}$, Sidiki Keita ${ }^{1}$, Issa Traore ${ }^{1}$, Salia Coulibaly ${ }^{2}$, Fadima Tall ${ }^{3}$, \\ Daouda Diallo3, Oulematou Coulibaly ${ }^{3}$, Assitan Kone', Boubacar Kone1, \\ Mahamadou Bacary Coulibaly ${ }^{1}$, Daouda Konate ${ }^{4}$, Ismael Konare ${ }^{1}$, Drissa Traore $^{1}$
}

\author{
${ }^{1}$ General Surgery Department, Kati, Mali \\ ${ }^{2}$ Medical Imaging Department, Kati, Mali \\ ${ }^{3}$ Anesthesia Resuscitation Department, Kati, Mali \\ ${ }^{4}$ Ophthalmology Department, Kati, Mali \\ Email: ^koniskeita73@gmail.com
}

How to cite this paper: Koniba, K., Diarra, A., Keita, S., Traore, I., Coulibaly, S., Tall, F., Diallo, D., Coulibaly, O., Kone, A., Kone, B., Coulibaly, M.B., Konate, D., Konare, I. and Traore, D. (2019) Ileal Occlusion on Bezoars at Kati BSS Hospital. Surgical Science, 10, 39-43.

https://doi.org/10.4236/ss.2019.101005

Received: November 12, 2018

Accepted: January 25, 2019

Published: January 28, 2019

Copyright $\odot 2019$ by author(s) and Scientific Research Publishing Inc. This work is licensed under the Creative Commons Attribution-NonCommercial International License (CC BY-NC 4.0). http://creativecommons.org/licenses/by-nc/4.0/ (c) (i) \&) Open Access

\begin{abstract}
Bowel occlusions by bezoars are rare pathologies. They are due to an obstruction of the intestinal lumen by a solid mass of fruits or undigested vegetable fibers. They are seasonal (wild fruit season from March to June) in the Sahel Zone. We report a case of small bowel obstruction in a 35-year-old rural man after swallowing a significant amount of wild grapes (Lannea microcarpa). We proceeded to the resection of the occluded ileal segment and performed an ileal terminal ileal anastomosis. There weren't any complications during the postoperative site.
\end{abstract}

\section{Keywords \\ Bezoars, Occlusion, Jejunum, Season}

\section{Introduction}

Bezoar is a solid mass of undigested fruit, grain of fruit or vegetable fiber, obstructing a segment of the digestive tract [1]. It is a rare etiology of intestinal obstructions [2] [3]. If the trichobezoar is seen in patients with psychic troubles [4], the phytobezoar is generally also found in those with an antecedent digestive surgery [2]. The treatment is essentially surgical. This observation finds its interest in the fact that the patient had not any particular antecedent. We report a case found in the General Surgery Department of Kati SBB CHU.

\section{Observation}

He was a 39-year-old man with no particular history, who was received an emergency for painful abdominal distension, like cramps with early postprandial 
vomiting. The symptomatology evolved for two days with stopping of materials and gases. On anamnesis, the patient reported having swallowed a large quantity of wild grapes (Lannea microcarpa) two days earlier. After swallowing, this symptomatology began. In Africa, in the savannah zone, the fruits of Lannea microcarpa mature from March to April. These fruits are widely swallowed by people during the dry season. At the arrival of the patient, we noted a blood pressure of 110/80 $\mathrm{mm} \mathrm{Hg}$, an arterial pulse at 99 beats per minute, good mucosal staining. On clinical testing, we observed a weak symmetrical abdominal meteorism with intermittent peristaltic ripples. There was no laparotomy scar. On palpation, the patient showed a painful and generalized abdominal defense with a shriek of the umbilicus. Abdominal percussion was noted with umbilical tympanism. Orifice hernias were free and the ampulla Rectal was empty in rectal testing with a non-convex, non-painful Douglas. The rest of the somatic testing has not any particular sign. Abdominal X-rays without preparation of the abdomen were observed to have central, higher-than-wide, central hydroaerative levels plotted for hail occlusion (Figure 1). The biological assessment was normal out of aprothrombin rate of $52 \%$ (Standard $>70 \%$ ). We proceeded to a medial laparotomy under and above the umbilical. During the exploration, the patient had a hard, elongated, intraluminal mass that obstructed the ileum (Figure 2). The obstructed area had a depitonized inflammatory aspect. The obstruction was located $40 \mathrm{~cm}$ from the ileocecal junction. The rest of the ileum was normal. A short ileotomy revealed a solid mass of undigested wild grapes (Figure 3). We proceeded to an ileal resection with $30 \mathrm{~cm}$ of the occluded ileum and an ilealendobondinal anastomosis. The postoperative result was simple.

\section{Discussion}

Bezoar is a concretion of plant fibers (orange pulp, coconut, figs...) that forms in the gastrointestinal lumen [5]. The origin of this term is still unknown, it derives from Persian padzar, Arabic bedzher, Turkish parzehir meaning antidote [6].

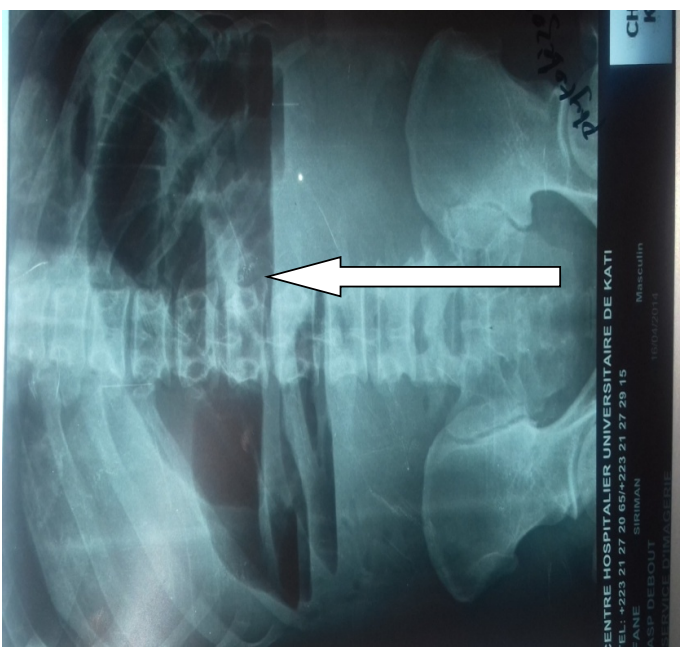

Figure 1. X-ray of the abdomen without preparation. 


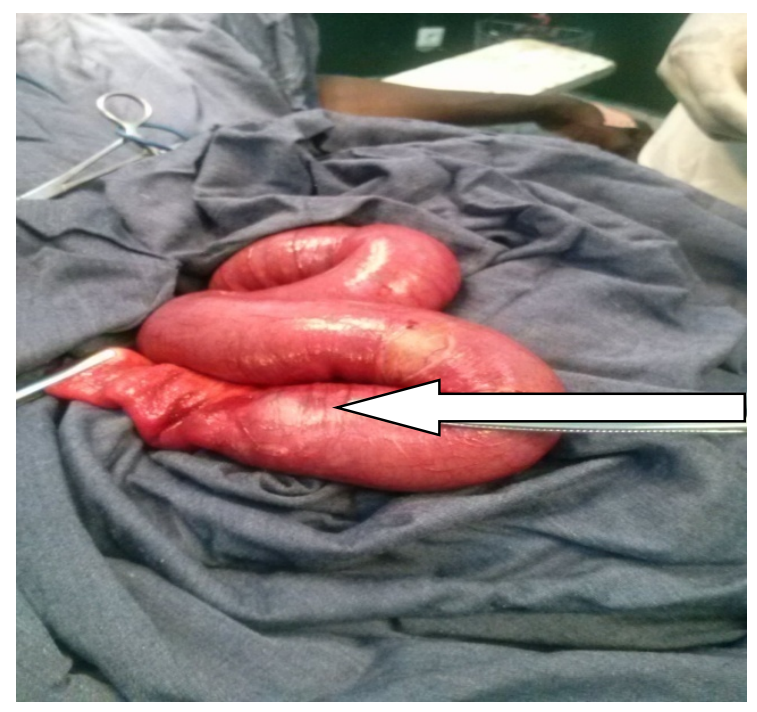

Figure 2. Intraluminal mass, hard, elongated.

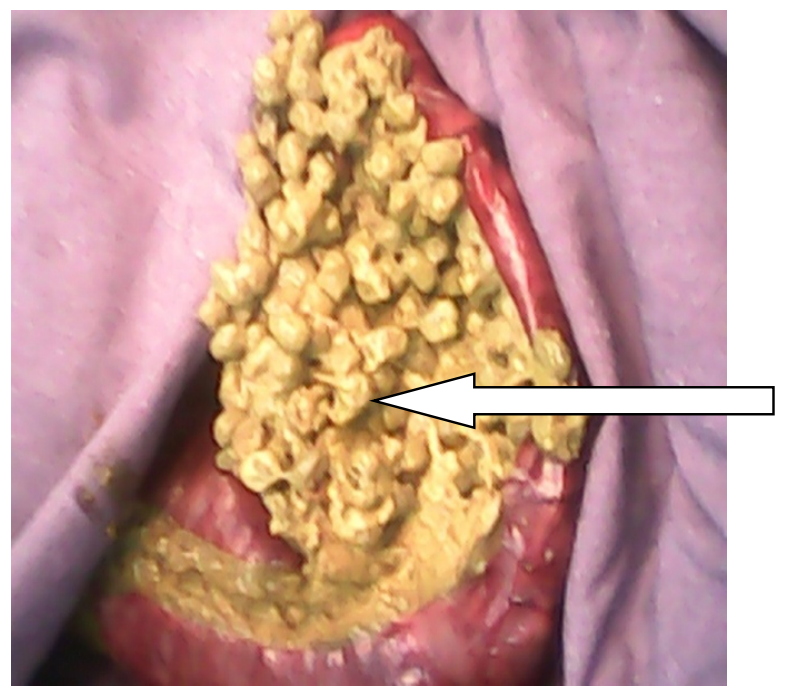

Figure 3. Intra-ileal Lannea microcarpa grains obstructing the ileum.

Formerly bezoars extracted from the stomach of goats were used in the treatment of numerous diseases (epilepsy, leprosy...) [7]. It is a rare cause of intestinal obstruction in human beings [1] [2] [3]. Trichobezoar (concretions of hair, carpet fibers) mainly obstruct the stomach, according to Laraja RD [8] plant debris are responsible for $2.9 \%$ of obstructive occlusions. Coll [9] observed that $56 \%$ of patients suffered from intestinal occlusions by bezoar had an antecedent gastrointestinal surgery and more particularly gastrectomy with gastroduodenal anastomosis. Our patient had not any antecedent digestive surgery. The wild grape (Lannea microcarpa) is a popular fruit well liked by the rural people in the savannah areas of West Africa (Mali, Burkina Faso, Niger and Senegal). According to Rakotova M [2], in Madagascar, Khaki, another wild fruit that is responsible for intestinal occlusions by bezoar. Note that the fruits of wild grapes Lannea microcarpa give hard walnuts, not digestible covered with a soft but 
sticky flesh. Once swallowed, the grains tend to clump against each other to form an opaque mass. As BALIAN [10] said: the symptomatology is vague dominated by abdominal pains, constipation, abdominal meteorism, early postprandial vomiting, stopping of materials and gaseslater. The diagnosis of occlusion of hail by bezoar is generally made intraoperatively because in our countries, it is the radiography of the abdomen without preparation that we often have. On the other hand, the scanner will be a very valuable contribution [3]. We performed the immediate anastomosis resection in our patient. If conventional surgery is the only alternative in the advanced intestinal localization of bezoar, the authors [2] [10] [11] reported some cases of chemical dissolution by acetylcysteine, papain or cellulose or Coca Cola. If surgical removal by enterotomy or anterograde emptying is often possible [3], we proceeded to an ilealendo-ileal anastomosis resection, considering the inflammatory aspect of the loop. We did not find any other phytobezoar location sites in the patient. After one year and six months of decline, the patient was doing well.

\section{Conclusion}

Intestinal obstruction by ingestion of wild-type (Lannea microcarpa) is rare. It seasonally happens in Africa. Chemical dissolution is an alternative but surgery remains the only sentence in advanced forms.

\section{Conflicts of Interest}

The authors declare no conflicts of interest regarding the publication of this paper.

\section{References}

[1] Bakey, M. and Ochsner, A. (1938) Bezoars and Concretions. Surgery, 4, 934-963.

[2] Rakotovao, M., Solofaarinana, E., Razafimahatratra, R., Rakotosolofo, A., Samison, L.H. and Rakokto-Ratsimba, H.N. (2009) An Observation of Jejunal Occlusion on Phytobezoard in Madagascar. Tropical Surgery Review, 3, 29-31.

[3] Sanou, A., Zongo, N., Tinto, S., Bonkoungou, P.G., Kaboré, A.R.F., Zida, M., Traore, S.S. and Sanou, D. (2013) Acute Seasonal Intestinal Obstruction.

[4] Mountassir, M., Tarikennafae, Z., Hichamouzzad, I. and el kandrysifeddine, O. (2011) A Case of Gastric Trichobeozzard, General Surgery Service, Guelmim 5th Military Hospital, Morocco. The Pan African Medical Journal, 9, 19.

[5] Emmerson, A.P. (1989) Foods High in fiber And Bezoartraining. Journal of the American Dietetic Association, 87, 1675-1677.

[6] Rees, M. (1984) Intussusception Caused by Multiple Trichobezoars: A Surgical Trap for the Unwary. British Journal of Surgery, 71, 721. https://doi.org/10.1002/bjs.1800710927

[7] Lee, J. (1996) Bezoards and Foreignbodies of the Stomach. Gastrointestinal Endoscopy Clinics of North America, 6, 605-619. https://doi.org/10.1016/S1052-5157(18)30357-X

[8] Laraja, R.D., Usai, A., Pryce, E. and Cioroiv, M. (1990) Intestinal Obstruction Secondary to Bezoars. New York State Journal of Medicine, 90, 561-562. 
[9] Coll, J.R. (1989) Small Bowel Obstructions Due to Bezoar in the Intact Gastrointestinal Tract. The Journal of the Royal College of Physicians of Edinburgh, 34, 267-269.

[10] Balian, A., Chatelon, J., Carloni, A., El Naggar, A. and Njike, M. (2006) Rare Gastric Pathology (Bezoar, Volvulus, Duplication, Diverticulum, Rupture). Encyclopédie Médico Chirurgicale, Gastroenterologie, B-10, 9-031.

[11] Serme, A.K. (2002) Bezoars of the Esophagus: About an Observation of an African Black Man in Burkina Faso. Médecine d Afrique Noire, 49, 548-550. 